\title{
1 Evidence for chaotropicity/kosmotropicity offset in a yeast growth model
}

2

3 Joshua Eardley ${ }^{1}$, Cinzia Dedi ${ }^{1}$, Marcus Dymond $^{1}$, John E. Hallsworth ${ }^{2}$ \& David J. Timson ${ }^{1,{ }^{*}}$

$4{ }^{1}$ School of Pharmacy and Biomolecular Sciences, University of Brighton, Huxley Building, Lewes

5 Road, Brighton, BN2 4GJ. UK

$6{ }^{2}$ School of Biological Sciences and Institute for Global Food Security, Queen's University Belfast, 19 7 Chlorine Gardens, Belfast, BT9 5DL. UK.

$8 \quad *$ Corresponding author (phone: +44(0)1273641623; email: d.timson@brighton.ac.uk) 
11 Chaotropes are compounds which cause the disordering, unfolding and denaturation of biological macromolecules. It is the chaotropicity of fermentation products that often acts as the primary limiting factor in ethanol and butanol fermentations. Since ethanol is mildly chaotropic at low concentrations, it prevents the growth of the producing microbes via its impacts on a variety of macromolecular systems and their functions. Kosmotropes have the opposite effect to chaotropes and we hypothesised that it might be possible to use these to mitigate chaotrope-induced inhibition of Saccharomyces cerevisiae growth. We also postulated that kosmotrope-mediated mitigation of chaotropicity is not quantitatively predictable. The chaotropes ethanol and urea, and compatible solutes glycerol and betaine (kosmotrope), and the highly kosmotropic salt ammonium sulphate all inhibited the growth rate of Saccharomyces cerevisiae in the concentration range 5-15\%. They resulted in increased lag times, decreased maximum specific growth rates, and decreased final optical densities. Surprisingly, neither the stress protectants nor ammonium sulphate reduced the inhibition of growth caused by ethanol. Whereas, in some cases, compatible solutes and kosmotropes mitigated against the inhibitory effects of urea. However, this effect was not mathematically additive from the quantification of chao-/kosmotropicity of each individual compound. The potential effects of glycerol, betaine and/or ammonium sulphate may have been reduced or masked by the metabolic production of compatible solutes. It may nevertheless be that the addition of kosmotropes to fermentations which produce chaotropic products can enhance metabolic activity, growth rate, and/or product formation.

Keywords: entropy, biofuel, Saccharomyces cerevisiae, urea, glycerol, ammonium sulphate 
Chaotropes are compounds which cause the disordering of other molecular structures (Cray et al. 2013). Of particular biochemical relevance are those which entropically disorder, and can unfold, biological macromolecules such as proteins and nucleic acids (Bennion and Daggett 2003; Das and Mukhopadhyay 2009; Salvi et al. 2005). Experimentally, the chaotropic properties of compounds such as urea, guanidium hydrochloride and propidium iodide have been widely exploited to denature proteins and in the purification of nucleic acids (Boom et al. 1990; Pace 1986; Van Ness and Chen 1991). Urea is naturally produced by mammals as the end-product of the deamination of amino acids via the urea cycle (Krebs 1942). This avoids the accumulation of highly toxic ammonia, but the urea itself must also be removed by excretion in the urine to avoid excessive build-up. In contrast, kosmotropes promote the ordering of molecules in solution, often resulting in increased rigidity and stability (Kella and Kinsella 1988). Glycerol is often used to protect proteins in solution (e.g. in commercially supplied restriction endonucleases) (Vagenende et al. 2009). This compound, along with proline, betaine and trehalose, is also produced naturally by many micro-organisms as a compatible solute as a response to osmotic stress, (Brown 1978; Brown 1990; Brown and Simpson 1972). Although glycerol is not kosmotropic, it has been shown to reduce the adverse effects of ethanol on fungal systems (Bhaganna et al. 2010; de Lima Alves et al. 2015; Hallsworth 1998; Hallsworth et al. 2003). Ammonium sulphate is routinely used for the precipitation and preservation of proteins in the laboratory, an application which relies partly on its kosmotropic properties (Wingfield 1998).

Chaotropicity also has significant implications for industrial fermentations. By far the most common fermentation is the production of ethanol by yeasts or other micro-organisms. This process is required in the production of alcoholic drinks and ethanol-based biofuels. Ethanol is produced naturally by some micro-organisms to inhibit or kill competing species, primarily through its chaotropic effects. However, in fermentations, as the level of ethanol rises it also becomes increasingly inhibitory to the yeasts which produce it. Most industrial strains of Saccharomyces cerevisiae can tolerate up to approximately $15 \%(\mathrm{v} / \mathrm{v})$ ethanol before growth largely ceases and the cells begin to die. Thus, the chaotropicity of ethanol sets upper limits on both the rate of ethanol production and the final ethanol yield which can be produced through batch fermentation (Cray et al. 2015).

The molecular mechanisms of chaotropic activity have not been well-studied for many of the chemically diverse chaotropic stressors, but it is well-known that mechanisms may differ (Ball and Hallsworth 2015; Cray et al. 2013; Cray et al. 2015). It has been suggested that chaotropes such as urea compete effectively for hydrogen bond donors in proteins, thus destabilising secondary structural elements such as $\alpha$-helices (Bennion and Daggett 2003; Salvi et al. 2005). It has also been assumed that chaotropes act as water-structure breakers for pure solutions of the chaotrope. This assumption is not consistent with the original usage of 'chaotrope' (a substance that disorders biomacromolecules), the experience of the microbial cell, or recent data on the physics of water in the presence of chaotropes (Ball and Hallsworth 2015). Some studies, for example, have suggested that chaotropes increase the overall entropy of the solution, reducing the thermodynamic penalty for the unfolding of proteins (Hatefi and Hanstein 1969; Kresheck and Benjamin 1964; Moelbert et al. 2004; Rupley 1964). Some authors have used molar solution entropies as a proxy measure, but this would only be valid if increased entropy of the system is the principal cause of chaotropicity (Aviram 1973; Miyawaki and Tatsuno 2011). Empirical measures have also been proposed which measure the effects of dissolved compounds on macromolecules. The most-extensive scale utilises the gelation point of agar and spans highly chaotropic compounds such as guanidine hydrochloride 
to highly kosmotropic compounds such as ammonium sulphate. The method also permits the ranking of different types of compounds including non-polar, barely water-soluble compounds such as benzene, polar organic molecules such as alcohols and ionic compounds such as magnesium sulphate. This scale broadly correlates with other measures, including solution entropies, suggesting common, underlying mechanisms for the various empirical effects observed (Cray et al. 2013). Interestingly, this scale suggests that glycerol behaves unusually. At lower concentration $(<5 M)$, it is relatively "neutral" on the scale with a molar chaotropicity close to zero. However, at higher concentrations, its molar chaotropicity is comparable to ethanol (Cray et al. 2013).

That it is possible to quantify chaotropicity leads to some intriguing questions. Many other scales are additive, for example, thermodynamic quantities such as free energy, enthalpy and entropy. Even in cases where quantities cannot be added, there are generally ways of calculating the overall value for a mixture (e.g. the $\mathrm{pH}$ scale of acidity and alkalinity). However, the interactions between and within biomacrmolecules, water and solutes are complex and dynamic and - for mixtures of solutes - not readily predictable. Furthermore, living cells produce compatible solutes, many of which are kosmotropic (e.g. trehalose), and two of which are chaotropic at sufficient concentration (glycerol and fructose). Therefore, we hypothesized that-chaotropicity and kosmotropicity values for individual substances could not be added or subtracted to predict the impacts of solute mixtures on the cellular system. We also postulated that kosmotrope-mediated mitigation of chaotropicity is not quantitatively predictable. Here, we describe experiments to test these postulates by measuring the effects of chaotropes, kosmotropes and mixtures thereof on the growth of yeast in liquid culture.

\section{Materials and Methods}

\section{Yeast strain, growth media and compounds}

Saccharomyces cerevisiae NCYC 1088 is a non-floculating ale strain, deposited in the UK National Collection of Yeast Cultures (NCYC) in 1958 by a British Brewery (NCYC 2019). It was stored at $4{ }^{\circ} \mathrm{C}$ on Sabouraud Dextrose Agar (SDA) plates (Oxoid) and grown in Yeast Peptone Dextrose broth (YPD broth; yeast extract $10 \mathrm{gl}^{1}$, bacteriological Peptone from meat $20 \mathrm{gl}^{-1}$, glucose $20 \mathrm{gl}^{-1}$; Sigma Aldrich Chemical Company). Ethanol, urea, betaine, ammonium sulphate and glycerol (87\%) were all obtained from Sigma Aldrich Chemical Company.

\section{Yeast growth measurements}

A single colony of S. cerevisiae NCYC 1088 was used to inoculate $10 \mathrm{ml}$ of YPD broth-and incubated overnight at $30^{\circ} \mathrm{C}$ with shaking $(125 \mathrm{rpm})$. When an $\mathrm{OD}_{620 \mathrm{~nm}}$ of 1 was reached the culture was diluted 1 in 10 with YPD broth and added to a well in a microplate (Thermo Scientific) containing no added compound (control), or glycerol betaine or ammonium sulphate so that the final dilution of yeast was 1 in 100.

The compounds were dissolved in YPD broth-then filter sterilised. Further dilutions were prepared to give a final concentration range of added solutes in the wells of between $2.5 \%$ and $15 \%$ ( $\mathrm{v} / \mathrm{v}$ for liquids and $\mathrm{w} / \mathrm{v}$ for solids). Each dilution was tested in triplicate on two to four separate occasions. The microplate was covered in a non-gas permeable film (Thermo Scientific) to prevent evaporation. Growth of the yeast was measured using an Ascent iEMS Multiskan microplate reader (Thermo Lab Systems) at $30^{\circ} \mathrm{C}$ with shaking. Optical density measurements at a wavelength of $620 \mathrm{~nm}$ were taken every $15 \mathrm{~min}$, for a period of $72 \mathrm{~h}$. 
To aid visual analysis, the Weibull growth model (equation 1) was applied in GraphPad Prism 6 (GraphPad Software, CA, USA) to the growth curve data.

$O D=O D_{\max }-\left(O D_{\max }-O D_{\min }\right) \exp (-k t)^{g}($ Equation 1)

The Weibull distribution is an empirical mathematical model that takes into account the lag, exponential and stationary phases of growth. It is however not able to capture the decline in $O D_{600 \mathrm{~nm}}$ observed at the end of the cultivation; the equation requires adjustment to include a term for cell death (Bevilacqua et al. 2015; Coroller et al. 2006). Growth parameters (lag time, $t_{\text {lag; maximum }}$ specific growth rate, $\mu_{\max }$ and final optical density, $O D_{\text {final }}$ ) were obtained by fitting the data to the Gompertz equation (2) using the Microsoft Excel Add-in DMFit, running under Windows (Gompertz 1825).

$O D=O D_{\min }+\left(O D_{\max }-O D_{\min }\right) \exp \left(-\exp \left(\left(2.718 \mu_{\max } /\left(O D_{\max }-O D_{\min }\right)\right)\left(t_{l a g}-t\right)+1\right)\right)$

(Equation 2)

For the comparison of growth parameters between controls and experiments, a one-way ANOVA was performed with Dunnet's multiple comparison post hoc test in GraphPad Prism 6.

\section{Results and Discussion}

In interpreting the growth curves, a number of assumptions were made. Any increase in $t_{\text {lag }}$ means that the initial environment is less favourable for growth to begin and the yeast cells had adapt to the conditions of the experiment. Any decrease in $\mu_{\max }$ means that the environment is less favourable for cell division. This could be because biomacromolecules are less functional due to unfolding or excessive rigidification. Alternatively, the cells may be forced to divert energy away from cell division and towards cellular homeostasis, e.g. synthesis of heat shock proteins to address protein unfolding. Any decrease in $\mathrm{OD}_{\text {final }}$ means that the yeast was less able to convert growth media into biomass.

Chaotropes, compatible solutes, and ammonium sulphate inhibit growth at high concentrations

At lower concentrations (up to $2.5 \%, \mathrm{v} / \mathrm{v}$ ), ethanol had little effect on the three growth parameters (Figure 1; Supplementary Figure S1). However, above $5 \%(v / v), t_{\text {lag }}$ was increased and $\mu_{\max }$ was decreased. At $12.5 \%(\mathrm{v} / \mathrm{v})$ and $15 \%(\mathrm{v} / \mathrm{v})$, little or no growth was observed over the course of the experiment (Supplementary Figure S1). These results were expected and consistent with the wellestablished inhibitory effects of ethanol on yeast growth. Urea had no significant effect on the growth parameters up to $7.5 \%(\mathrm{w} / \mathrm{v})$. Above $10 \%(\mathrm{w} / \mathrm{v})$, it almost completely inhibits the growth such that all three parameters could not be measured (Figure 1; Supplementary Figure S1). Glycerol has an inhibitory effect on growth at $10 \%(v / v)$, increasing $t_{\text {lag }}$ and decreasing $\mu_{\max }$ (Figure 2 ). Of all the solutes tested, betaine had the least effect at the concentrations tested, slightly increasing $t_{\text {lag }}$ at $15 \%(\mathrm{w} / \mathrm{v})$ (Figure 2; Supplementary Figure S1). Interestingly, both glycerol and betaine increase the $\mathrm{OD}_{\text {final }}$ at $2.5 \%(\mathrm{v} / \mathrm{v})$ and $2.5 \%(\mathrm{w} / \mathrm{v})$ respectively (Figure 2; Supplementary Figure S1). This may result from the utilisation of these compounds as a carbon source by the yeast, or from their roles within the cell as protectants of macromolecular structures against chaotropicity and/or other stresses. At 
$\mathrm{OD}_{\text {final }}$ (Figure 2). This kosmotropic compound has previously been shown to inhibit the growth of the bacterium Pseudomonas putida and the filamentous fungus Fusarium coeruleum (Bhaganna et al. 2010; Cray et al. 2016). That chao- and kosmotropes can both inhibit growth suggests that cells require optimal flexibility and mobility in their biomolecules: too great an increase in molecular flexibility (which may result in unfolding and the dissociation of supramolecular complexes) or too great in increase in molecular rigidity are both deleterious to the cell. In addition, all of the compounds tested also reduce water activity, and some of them (betaine and ammonium sulphate) cause osmotic stress, so chao-/kosmotropic-effects do not operate in isolation. It may also be that some of the added compounds are assimilated as a nutrient source.- Ethanol, glycerol and betaine can all act as carbon sources in some S. cerevisiae strains. However, the data deposited at NCYC on this strain suggests that, while ethanol can be utilised, glycerol cannot; there is no data on betaine (NCYC 2019). Ammonium sulphate can act as a nitrogen source. Thus, any inhibitory effects of these compounds might be partly offset by their nutritional benefits. Nevertheless, these results suggest that increasing the chaotropicity or the kosmotropicity of the media tends to inhibit yeast growth.

\section{Compatible solutes and ammonium sulphate did not mitigate against inhibition of growth under the} conditions tested

The effects of glycerol, betaine and ammonium sulphate were assessed at three ethanol concentrations $-5,7.5$ and $10 \%(v / v)$. These values were chosen since they have a clear effect on the growth parameters, but are sub-lethal and did not completely inhibit growth (Figure 1; Supplementary Figure S1). At all three ethanol concentrations, glycerol $(1.25 \%, \mathrm{v} / \mathrm{v}$ and $2.5 \%, \mathrm{v} / \mathrm{v})$, betaine $(1.25 \%, \mathrm{w} / \mathrm{v}$ and $2.5 \%, \mathrm{w} / \mathrm{v})$, and ammonium sulphate $(1.25 \%, \mathrm{w} / \mathrm{v}$ and $2.5 \%, \mathrm{w} / \mathrm{v})$ did not improve the growth parameters (Figure 3; Supplementary Figure S2). In some cases, ammonium sulphate caused a further deterioration in these parameters, increasing $t_{\text {lag }}$, decreasing $\mu_{\max }$ and decreasing $\mathrm{OD}_{\text {final }}$ when compared to ethanol only controls (Figure 3 ). At high concentrations, the chaotropicity of glycerol may act synergistically with the chaotropicity of ethanol; the osmotic stress induced by betaine may be inhibitory, and the ionic nature and/or kosmotropic activities of ammonium sulphate may act to impair yeast growth.

\section{Compatible solutes and ammonium sulphate can mitigate against yeast growth inhibition by urea}

Cultures grown in the presence of urea, typically had improved growth profiles in the presence of ammonium sulphate, glycerol or betaine. Growth curves were shifted leftwards and upwards compared to controls in urea only (Supplementary Figure S2). There were varying effects on the growth parameters (Figure 4). These depended on the added compound and the concentration of urea which varied from $5,7.5$ and $10 \%, \mathrm{w} / \mathrm{v}$ corresponding to molar concentrations of $0.83,1.25$ and $1.66 \mathrm{M}$, and to chaotropicities of $13.8,20.8$ and $27.6 \mathrm{~kJ} \mathrm{~kg}^{-1}$ (Cray et al. 2013), respectively. In some cases, but not all, they partially alleviated the effects of urea on the growth parameters. -Ammonium sulphate reduced $\mathrm{t}_{\text {lag }}$ at $10 \%(\mathrm{w} / \mathrm{v})$ urea, but not at lower concentrations of the chaotrope (Figure 4). At $7.5 \%(\mathrm{w} / \mathrm{v})$ urea, glycerol (at $1.25 \%, \mathrm{v} / \mathrm{v}$ and $2.5 \%, \mathrm{v} / \mathrm{v})$ and betaine $(2.5 \%, \mathrm{v} / \mathrm{v})$ both partially offset the effects on $\mu_{\max }$ when compared to urea only controls (Figure 4$)$. At $5 \%(w / v)$ urea, glycerol $(2.5 \%$, $\mathrm{v} / \mathrm{v})$; net chaotropicity $\left.14.1 \mathrm{~kJ} \mathrm{~kg}^{-1}\right)$ and ammonium sulphate $(1.25 \%, \mathrm{w} / \mathrm{v})$ and $2.5 \%(\mathrm{v} / \mathrm{v})$; offset the reduction of $\mathrm{OD}_{\text {final }}$ (Figure 4). While no added compound was able to completely offset the effects of urea at any of the concentrations tested, these results nevertheless demonstrate mitigation 
against chaotropicity. As predicted, the effects of chao- and kosmotropicity are not additive for this yeast model.

\section{Conclusions}

While the addition of kosmotropes can mitigate chaotropicity in some cases, the effect is not quantitatively predicted in this yeast model. This is broadly similar to the results observed in an isolated enzyme model. Here, both chaotropes and kosmotropes depressed the activity of the enzyme and combinations only partially restored activity in a minority of cases (Bell et al. 2013). However, relatively low concentrations of compatible solutes were used in this study, relative to those which can be found in microbial cells under stress. -If we had made an assumption that there is a linear relationship between these parameters and that chaotropicity (or kosmotropicity) in a mixture of compounds is additive, the current study would have disproved this. Some work in which chaotropicities have been determined empirically suggests that the relationships may be more complex (de Lima Alves et al. 2015; Fox-Powell et al. 2016; Yakimov et al. 2015). Further work to understand these relationships is necessary to inform quantitative studies on the mitigation of chaotropicity in biofuel production and other fermentations.

Furthermore, in the yeast growth model, the effects which were observed only applied in the case of urea: we observed no mitigation in the case of ethanol. The reasons for this will require further investigation. For example, in addition to being chaotropic, ethanol reduces water activity, although previous work has demonstrated that the mode of action of both compounds at low-to-moderate concentrations is chaotropic (de Lima Alves et al. 2015).

Mitigation by compatible solutes and kosmotropes against chaotrope-induced stresses have been reported in numerous studies of enzyme- and cellular systems (e.g. (Bhaganna et al. 2016; Bhaganna et al. 2010; Chin et al. 2010; Cray et al. 2016; Cray et al. 2015; de Lima Alves et al. 2015; Hallsworth 1998; Hallsworth et al. 2003; Hallsworth et al. 2007; La Cono et al. 2019; Stevenson et al. 2015; Stevenson et al. 2017; Williams and Hallsworth 2009; Yakimov et al. 2015). Many of these studies carried out "testing-to-destruction" where enzyme or cellular systems were exposed to chaotropicity at the edge of their window for tolerance. Under these extreme circumstances, kosmotropic compatible solutes and other kosmotropic substances, as well as glycerol, mitigated against chaotropicity. It may be that the $S$. cerevisiae cell produces sufficient compatible solutes under moderate stresses that exogenous compounds are not required or effective. Furthermore, it may be that some of the compounds added in the current study were utilised as nutrients (see above). Nevertheless, the data presented here do suggest that mitigation of chaotropicity during fermentations may be worth considering where this is a limiting factor. Future studies should concentrate on high ethanol concentrations where chaotropicity can induce cell-system failure.

\section{Acknowledgements}

$\mathrm{JE}$ is in receipt of a PhD studentship from the University of Brighton under the Universities Alliance Doctoral Training Alliance in Energy. We thank Dr Lucas Bowler for advice on yeast growth monitoring using the Ascent iEMS Multiskan microplate reader.

\section{Author contributions}


251 DJT conceived the project and drafted the manuscript, which was co-authored by JE, CD, MD and JEH. JE carried out the majority of the experimental work, assisted by $C D$ and supervised by MD and 253 DJT. JEH provided intellectual input and challenge. 
Figure 1: Summary of growth data in the presence of chaotropes. Each graph summarises the effects of ethanol or urea on the three key growth parameters $-t_{l a g}, \mu_{\max }$ and $O D_{\max }$. For each experimental run, the measurements were obtained in triplicate. Each point represents the mean value resulting from a single experiment. The horizontal line represents the mean of these experimental values and the error bars the standard deviations of these means. Where values were statistically significantly different from the control (no added ethanol or urea), this is shown as: $p<0.05^{*} ; p<0.01 * * ; p<0.001 * * *$. nd, not determinable (due to lack of growth under the conditions of the experiment)

Figure 2: Summary of growth data in the presence of compatible solutes and kosmotropes. Each graph summarises the effects of glycerol, ammonium sulphate or betaine on the three key growth parameters $-t_{\operatorname{lag}}, \mu_{\max }$ and $O D_{\max }$. For each experimental run, the measurements were obtained in triplicate. Each point represents the mean value resulting from a single experiment. The horizontal line represents the mean of these experimental values and the error bars the standard deviations of these means. Where values were statistically significantly different from the control (no added glycerol, ammonium sulphate or betaine), this is shown as: $p<0.05^{*} ; \mathrm{p}<0.01^{* *} ; \mathrm{p}<0.001^{* * *}$. betaine to yeast cultures growing in the presence of increasing concentrations of ethanol. For each experimental run, the measurements were obtained in triplicate. Each point represents the mean value resulting from a single experiment. The horizontal line represents the mean of these experimental values and the error bars the standard deviations of these means. Where values were statistically significantly different from the control (no added glycerol, ammonium sulphate or betaine), this is shown as: $p<0.05^{*} ; p<0.01 * * ; p<0.001 * * *$.

278 Figure 4: Summary of yeast growth data in the presence of ethanol and compatible solutes or

279 kosmotropes. Each graph summarises the effects of adding glycerol, ammonium sulphate (AMS) or betaine to yeast cultures growing in the presence of increasing concentrations of urea. For each experimental run, the measurements were obtained in triplicate. Each point represents the mean value resulting from a single experiment. The horizontal line represents the mean of these experimental values and the error bars the standard deviations of these means. Where values were statistically significantly different from the control (no added glycerol, ammonium sulphate or betaine), this is shown as: $p<0.05^{*} ; p<0.01 * * ; p<0.001 * * *$. 
Aviram I (1973) The interaction of chaotropic anions with acid ferricytochrome c J Biol Chem 248:1894-1896

Ball P, Hallsworth JE (2015) Water structure and chaotropicity: their uses, abuses and biological implications Phys Chem Chem Phys 17:8297-8305 doi:10.1039/c4cp04564e

Bell AN, Magill E, Hallsworth JE, Timson DJ (2013) Effects of alcohols and compatible solutes on the activity of $\beta$-galactosidase Appl Biochem Biotechnol 169:786-794 doi:10.1007/s12010-0120003-3

Bennion BJ, Daggett $V$ (2003) The molecular basis for the chemical denaturation of proteins by urea Proc Natl Acad Sci U S A 100:5142-5147 doi:10.1073/pnas.0930122100

Bevilacqua A, Speranza B, Sinigaglia M, Corbo MR (2015) A Focus on the Death Kinetics in Predictive Microbiology: Benefits and Limits of the Most Important Models and Some Tools Dealing with Their Application in Foods Foods (Basel, Switzerland) 4:565-580 doi:10.3390/foods4040565

Bhaganna P, Bielecka A, Molinari G, Hallsworth JE (2016) Protective role of glycerol against benzene stress: insights from the Pseudomonas putida proteome Curr Genet 62:419-429 doi:10.1007/s00294-015-0539-1

Bhaganna P et al. (2010) Hydrophobic substances induce water stress in microbial cells Microbial biotechnology 3:701-716 doi:10.1111/j.1751-7915.2010.00203.x; 10.1111/j.17517915.2010.00203.x

Boom R, Sol CJ, Salimans MM, Jansen CL, Wertheim-van Dillen PM, van der Noordaa J (1990) Rapid and simple method for purification of nucleic acids J Clin Microbiol 28:495-503

Brown AD (1978) Compatible solutes and extreme water stress in eukaryotic micro-organisms Advances in Microbial Physiology 17:181-242

Brown AD (1990) Microbial water stress physiology vol First. vol Book, Whole. Wiley, Chichester, UK Brown AD, Simpson JR (1972) Water relations of sugar-tolerant yeasts: the role of intracellular polyols Journal of general microbiology 72:589-591

Chin JP et al. (2010) Solutes determine the temperature windows for microbial survival and growth Proc Natl Acad Sci U S A 107:7835-7840 doi:10.1073/pnas.1000557107

Coroller L, Leguerinel I, Mettler E, Savy N, Mafart P (2006) General model, based on two mixed weibull distributions of bacterial resistance, for describing various shapes of inactivation curves Appl Environ Microbiol 72:6493-6502 doi:10.1128/aem.00876-06

Cray JA, Connor MC, Stevenson A, Houghton JD, Rangel DE, Cooke LR, Hallsworth JE (2016) Biocontrol agents promote growth of potato pathogens, depending on environmental conditions Microb Biotechnol 9:330-354 doi:10.1111/1751-7915.12349

Cray JA, Russell JT, Timson DJ, Singhal RS, Hallsworth JE (2013) A universal measure of chaotropicity and kosmotropicity Environ Microbiol 15:287-296 doi:10.1111/1462-2920.12018

Cray JA et al. (2015) Chaotropicity: a key factor in product tolerance of biofuel-producing microorganisms Curr Opin Biotechnol 33:228-259 doi:10.1016/j.copbio.2015.02.010

Das A, Mukhopadhyay C (2009) Urea-mediated protein denaturation: a consensus view The journal of physical chemistry B 113:12816-12824 doi:10.1021/jp906350s

de Lima Alves F et al. (2015) Concomitant osmotic and chaotropicity-induced stresses in Aspergillus wentii: compatible solutes determine the biotic window Curr Genet 61:457-477 doi:10.1007/s00294-015-0496-8

Fox-Powell MG, Hallsworth JE, Cousins CR, Cockell CS (2016) lonic Strength Is a Barrier to the Habitability of Mars Astrobiology 16:427-442 doi:10.1089/ast.2015.1432

Gompertz B (1825) On the Nature of the Function Expressive of the Law of Human Mortality, and on a New Mode of Determining the Value of Life Contingencies Phil Trans R Soc 115:513-585

Hallsworth JE (1998) Ethanol-induced water stress in yeast Journal of Fermentation and Bioengineering 85:125-137 doi:10.1016/S0922-338X(97)86756-6 
Hallsworth JE, Prior BA, Nomura Y, Iwahara M, Timmis KN (2003) Compatible solutes protect against chaotrope (ethanol)-induced, nonosmotic water stress Applied and Environmental Microbiology 69:7032-7034

Hallsworth JE et al. (2007) Limits of life in $\mathrm{MgCl}_{2}$-containing environments: chaotropicity defines the window Environmental microbiology 9:801-813 doi:10.1111/j.1462-2920.2006.01212.x

Hatefi Y, Hanstein WG (1969) Solubilization of particulate proteins and nonelectrolytes by chaotropic agents Proc Natl Acad Sci U S A 62:1129-1136

Kella NK, Kinsella JE (1988) Structural stability of $\beta$-lactoglobulin in the presence of kosmotropic salts. A kinetic and thermodynamic study Int J Pept Protein Res 32:396-405

Krebs HA (1942) Urea formation in mammalian liver Biochem J 36:758-767

Kresheck G, Benjamin L (1964) Calorimetric studies of the hydrophobic nature of several protein constituents and ovalbumin in water and in aqueous urea The Journal of Physical Chemistry 68:2476-2486

La Cono V et al. (2019) The discovery of Lake Hephaestus, the youngest athalassohaline deep-sea formation on Earth Sci Rep 9:1679 doi:10.1038/s41598-018-38444-z

Miyawaki O, Tatsuno M (2011) Thermodynamic analysis of alcohol effect on thermal stability of proteins Journal of bioscience and bioengineering 111:198-203 doi:10.1016/j.jbiosc.2010.09.007

Moelbert S, Normand B, De Los Rios P (2004) Kosmotropes and chaotropes: modelling preferential exclusion, binding and aggregate stability Biophys Chem 112:45-57 doi:10.1016/j.bpc.2004.06.012

NCYC (2019) NCYC 1088. National Centre for Yeast Cultures. https://www.ncyc.co.uk/catalogue/saccharomyces-cerevisiae-1088. Accessed 2 September 2019

Pace CN (1986) Determination and analysis of urea and guanidine hydrochloride denaturation curves Methods Enzymol 131:266-280

Rupley J (1964) The Effect of Urea and Amides upon Water Structure The Journal of Physical Chemistry 68:2002-2003

Salvi G, De Los Rios P, Vendruscolo M (2005) Effective interactions between chaotropic agents and proteins Proteins 61:492-499 doi:10.1002/prot.20626

Stevenson A et al. (2015) Is there a common water-activity limit for the three domains of life? The ISME journal 9:1333-1351 doi:10.1038/ismej.2014.219

Stevenson A et al. (2017) Glycerol enhances fungal germination at the water-activity limit for life Environ Microbiol 19:947-967 doi:10.1111/1462-2920.13530

Vagenende V, Yap MG, Trout BL (2009) Mechanisms of protein stabilization and prevention of protein aggregation by glycerol Biochemistry 48:11084-11096 doi:10.1021/bi900649t

Van Ness J, Chen L (1991) The use of oligodeoxynucleotide probes in chaotrope-based hybridization solutions Nucleic Acids Res 19:5143-5151

Williams JP, Hallsworth JE (2009) Limits of life in hostile environments: no barriers to biosphere function? Environmental microbiology 11:3292-3308 doi:10.1111/j.1462-2920.2009.02079.x

Wingfield $P$ (1998) Protein precipitation using ammonium sulfate Current protocols in protein science 13:A.3F.1-A.3F 8

Yakimov MM et al. (2015) Microbial community of the deep-sea brine Lake Kryos seawater-brine interface is active below the chaotropicity limit of life as revealed by recovery of mRNA Environ Microbiol 17:364-382 doi:10.1111/1462-2920.12587 


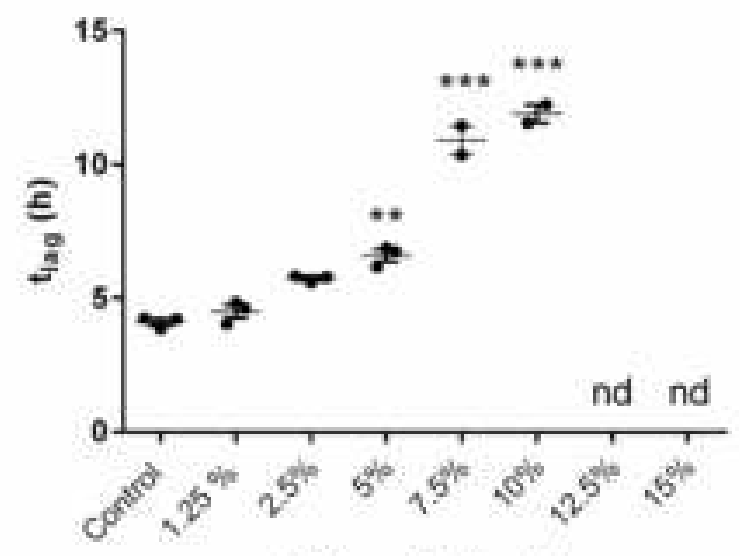

[Ethano] (\% v/v)

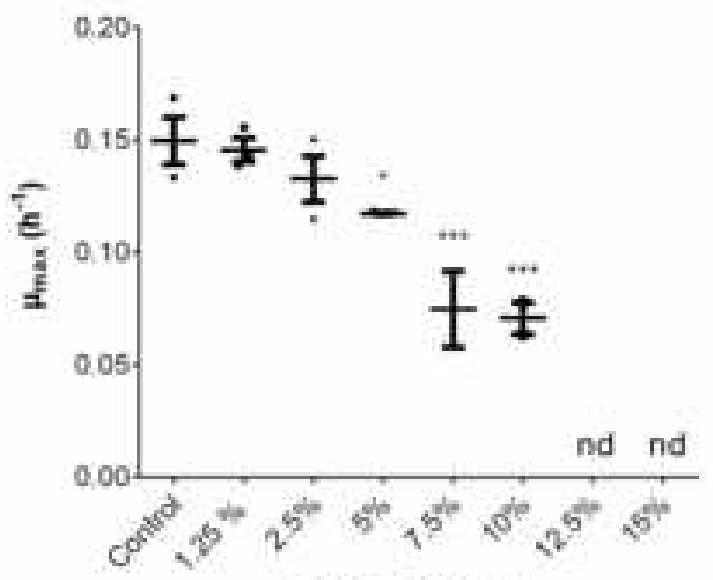

[Ethanol] (\% viv)

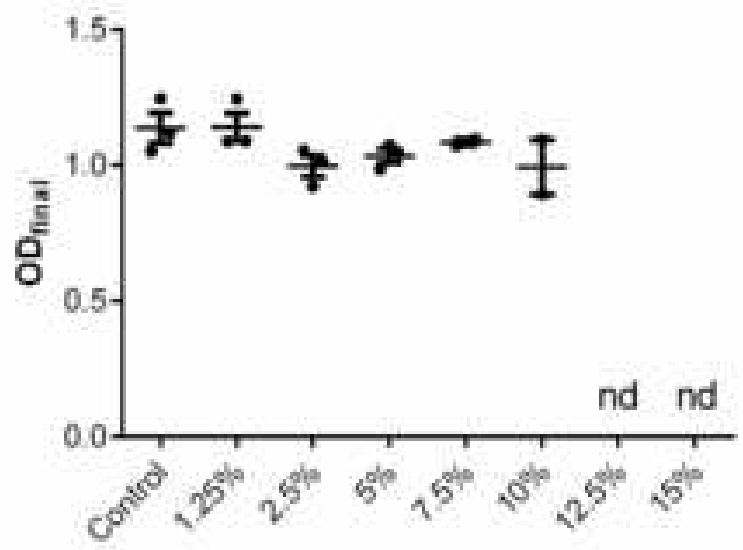

[Ethanol] $(\% \mathrm{v} / \mathrm{v})$

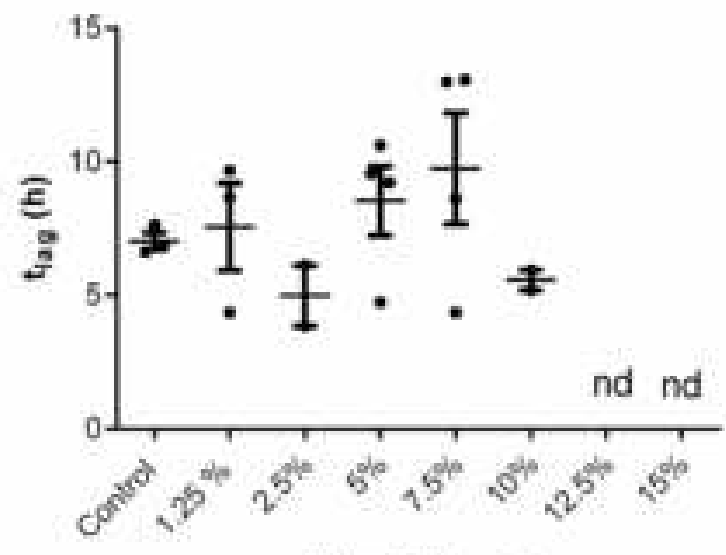

[Urea] (\% w/v)
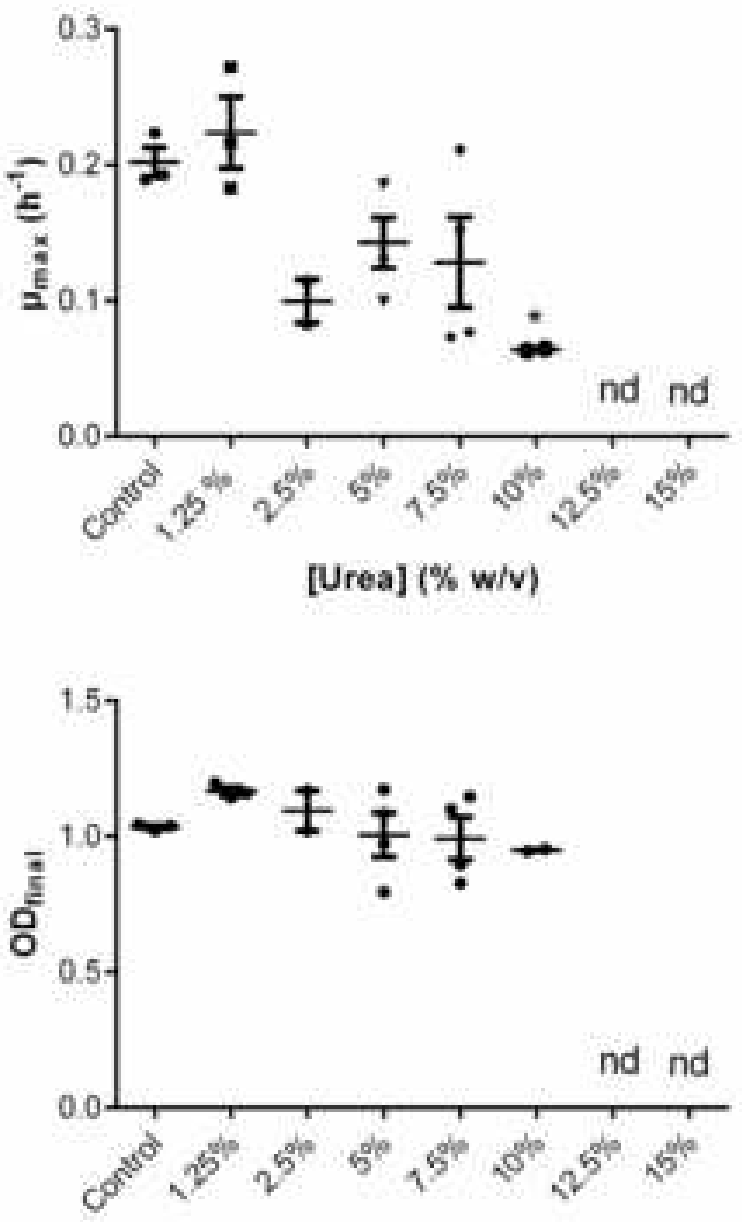

[Urea] $(\% w / v)$ 
Figure 2

Click here to access/download;Figure;Figure 2.tif $\underline{\underline{ }}$

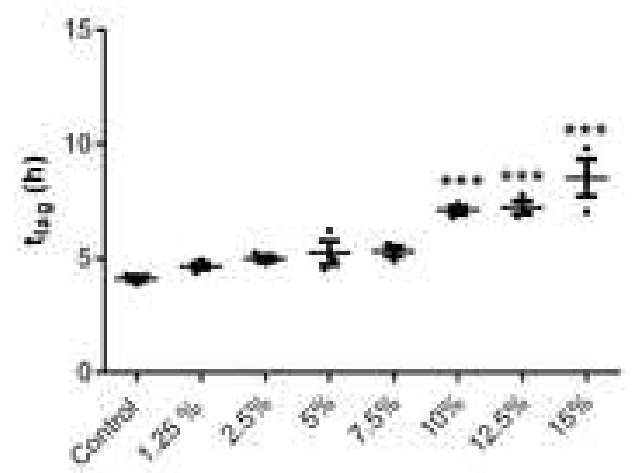

[Glycerol] (\% viv]

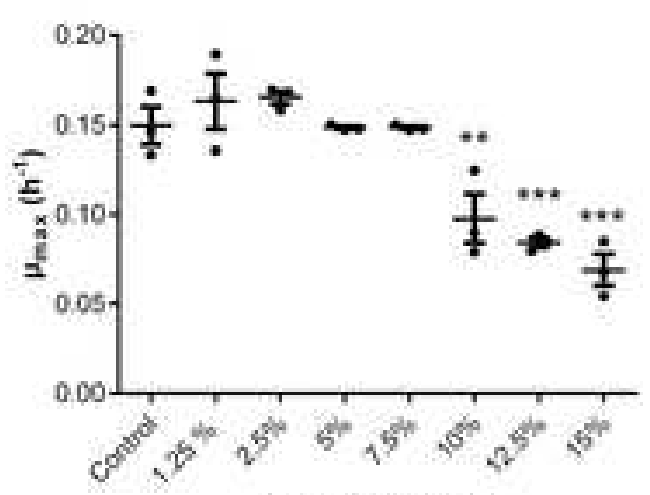

[Glycerol] (\% viv)

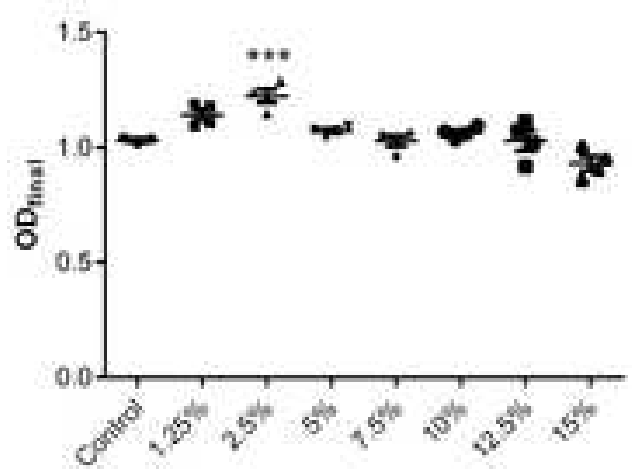

[Glycerol] (\% viv)

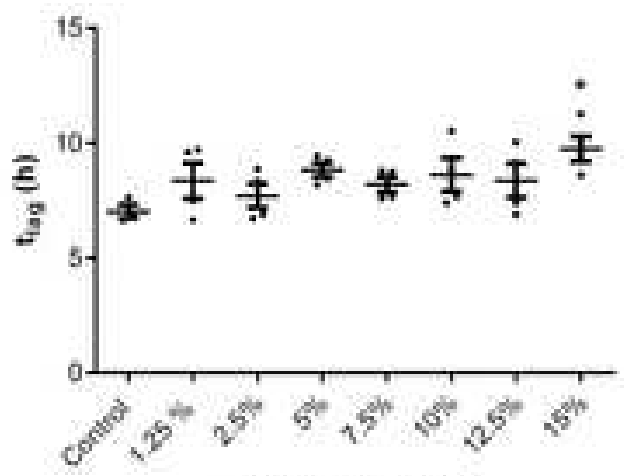

[Betaine] (\% wiv)

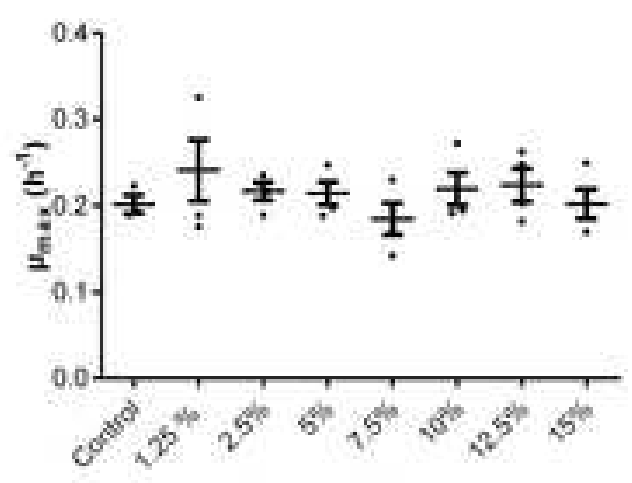

[Betaine] (\% v/v)

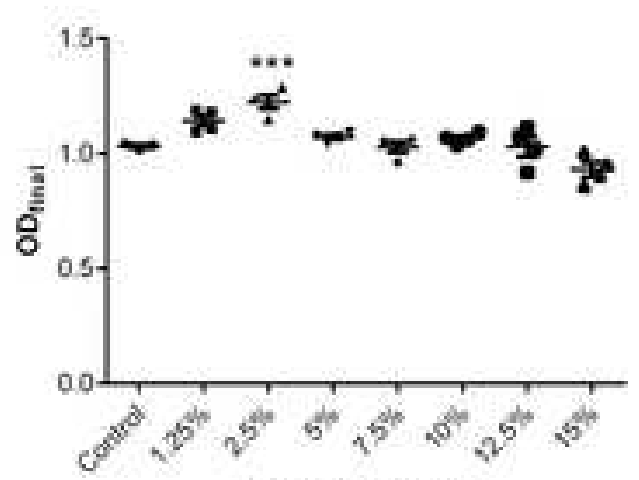

[Betaine] ( $\%$ wiv)

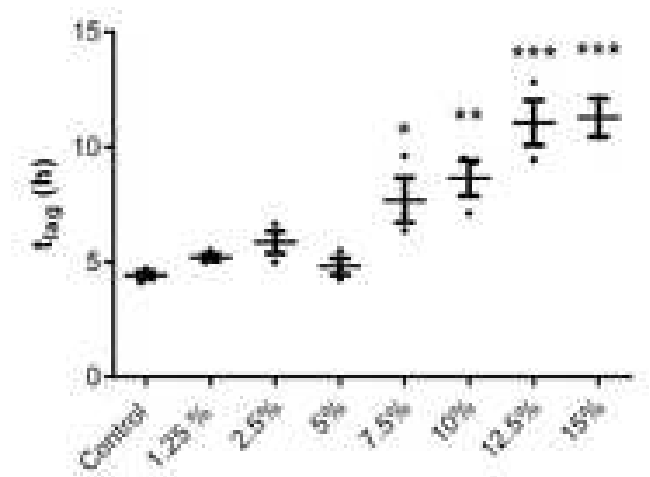

[Ammonium Sulphate] (\% w/v)

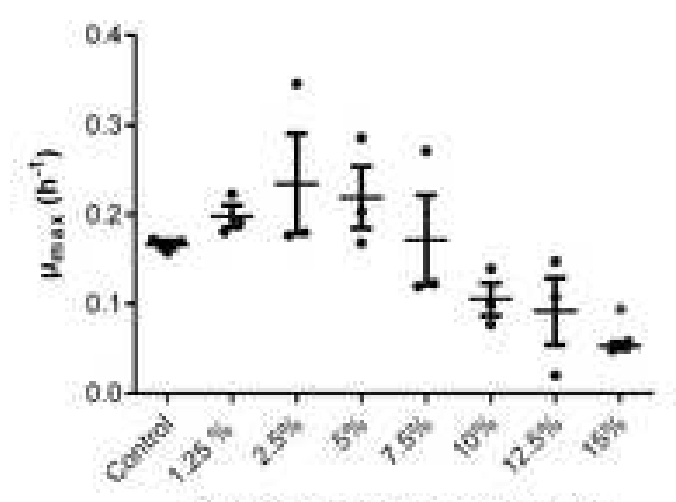

[Ammonium Sulphate] (\% wiv)

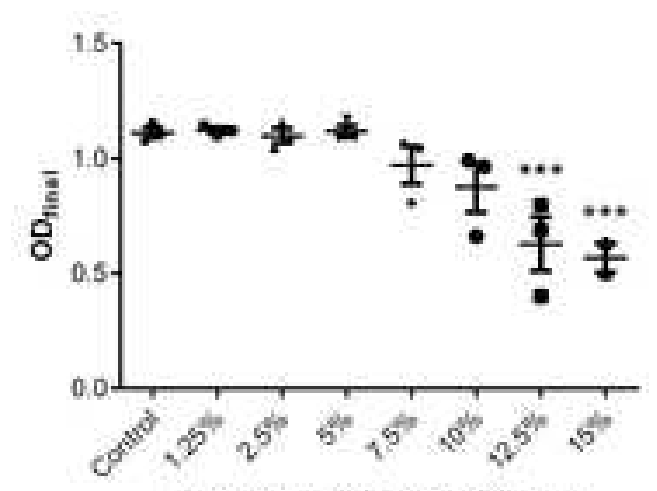

[Ammonium Sulphate] (\% wiv) 
$5 \%(\mathrm{v} / \mathrm{V})$ Ethanol

[Added Solute] ( $\%$ v/v or \% w/v)

$7.5 \%(\mathrm{v} / \mathrm{v})$ Ethanol

[Addod Soluto] [\% wiv of \% w/v)

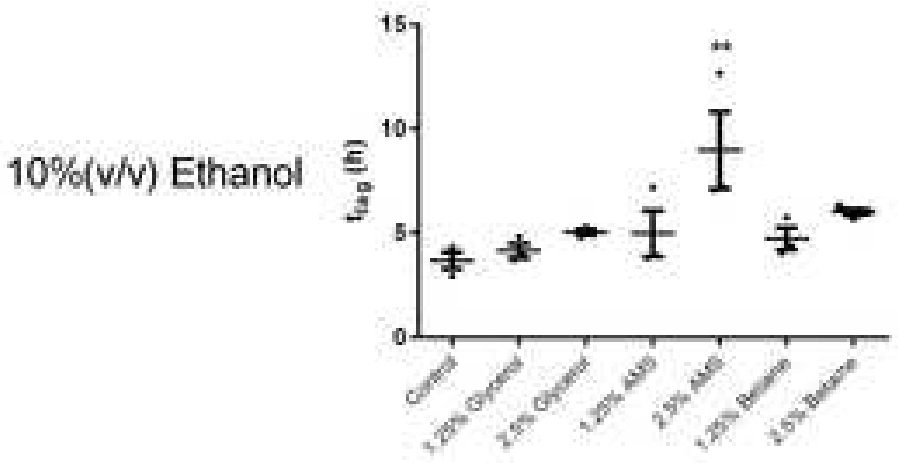

[Added Soluto] (\% viv or * w/v)

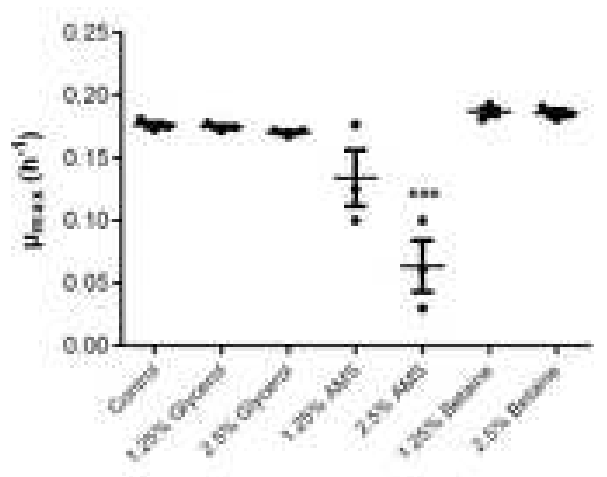

[Added Solute] (\% w/v or \% w/v)
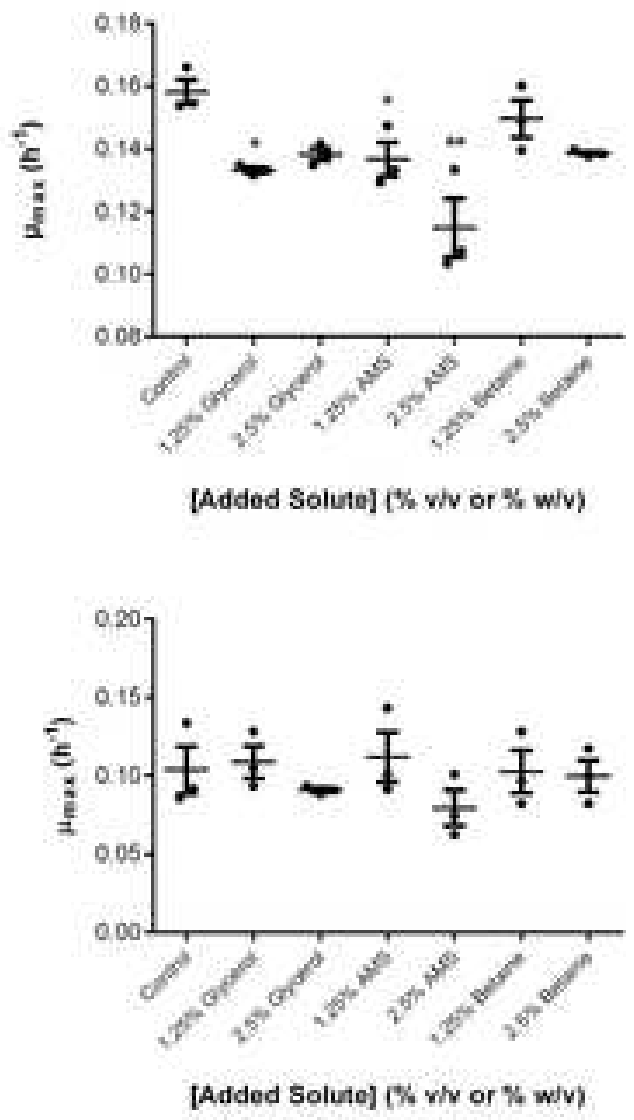

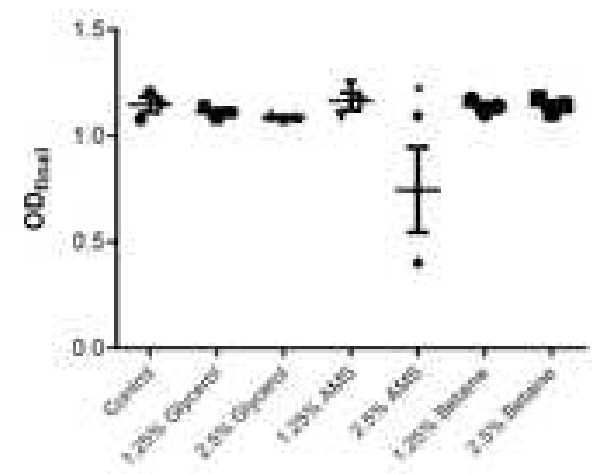

[Added Soluto] (\% viv or $\%$ w/v)

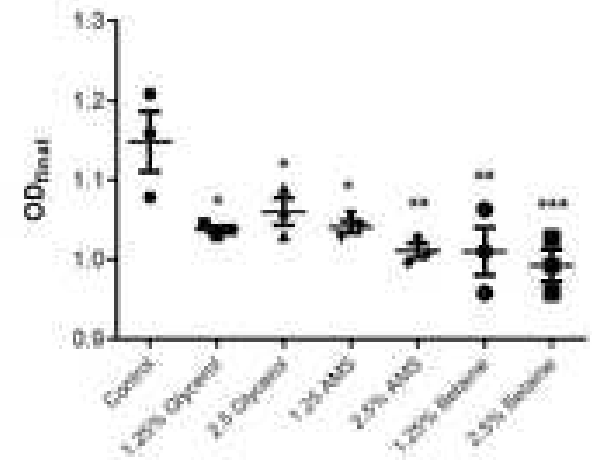

[Added Solutio] (\% wiY of \% v/V)

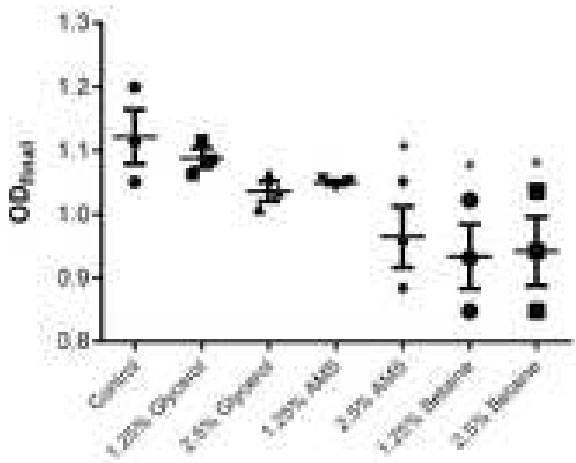

[Added Solute] (\% wiv or $\%$ v/V) 


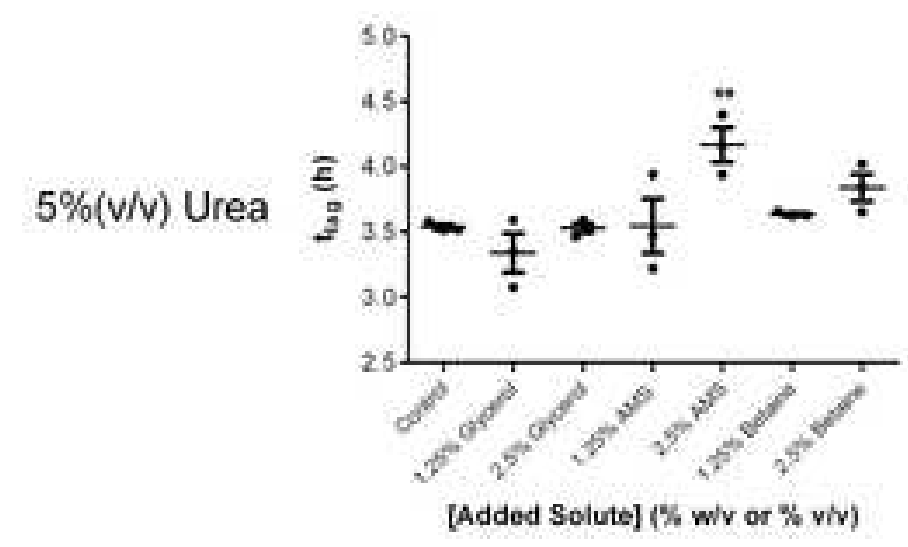

$7.5 \%(\mathrm{v} / \mathrm{v})$ Urea ${ }_{\text {[Added Solute] }(\% \text { wiv or } \% \text { viv) }}$

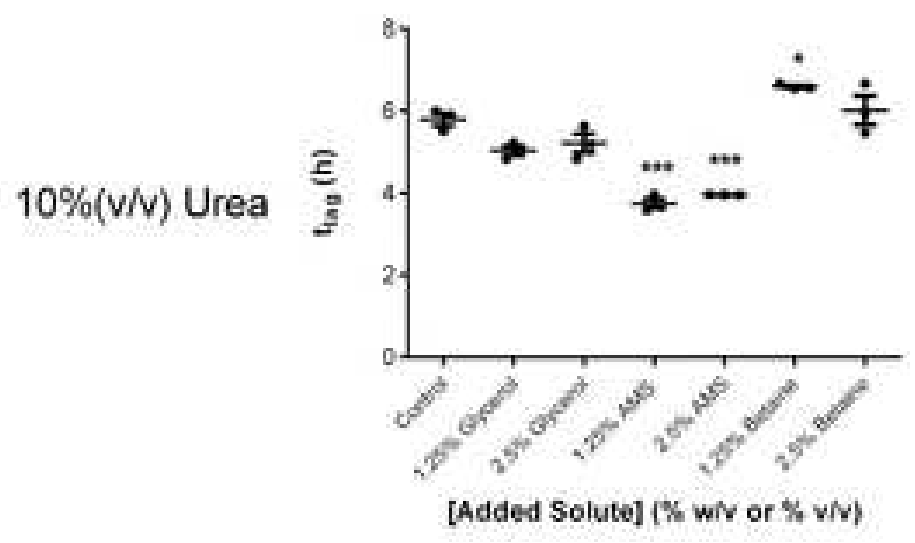

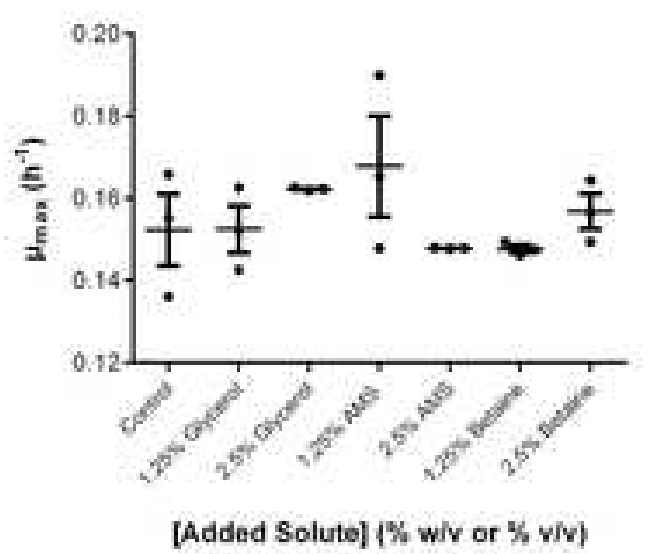
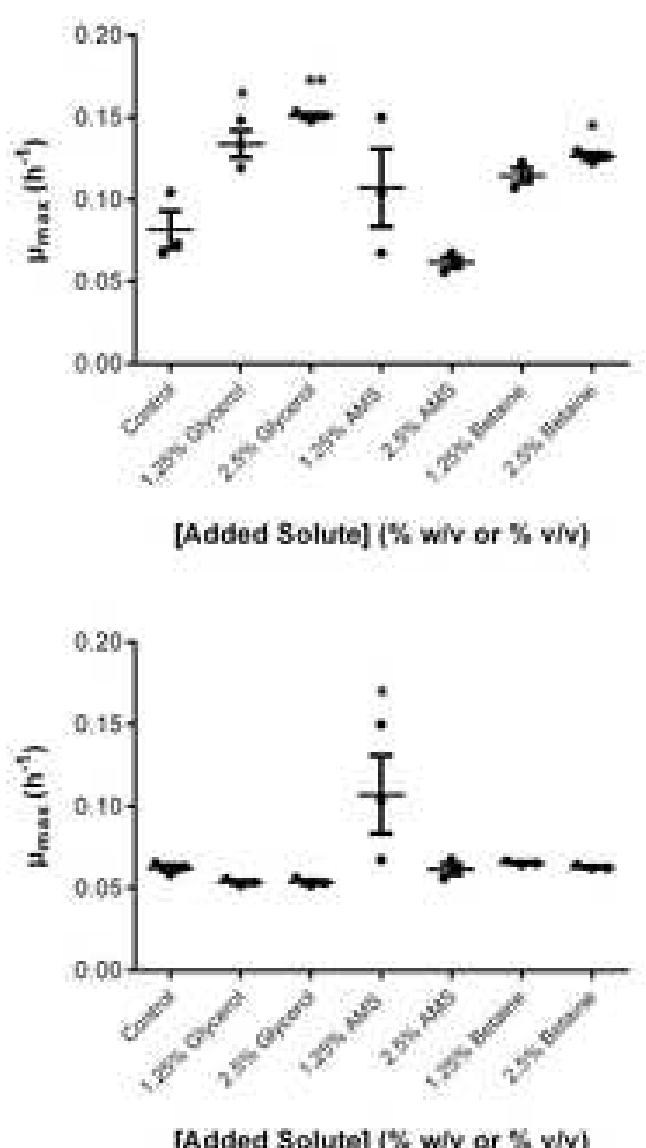

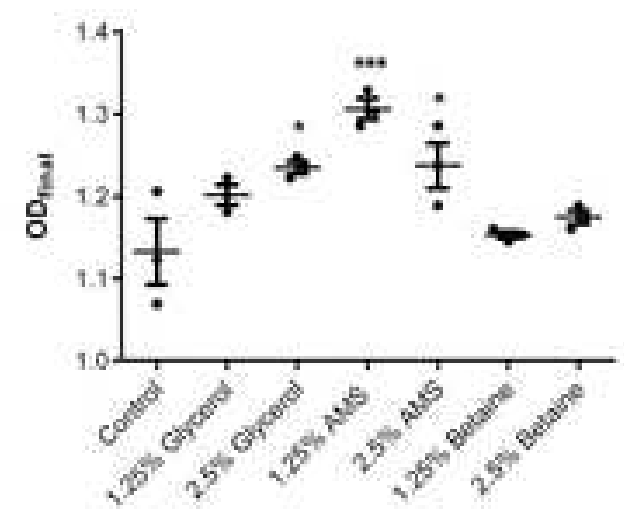

[Added Solute] [\% wiv or v/v)

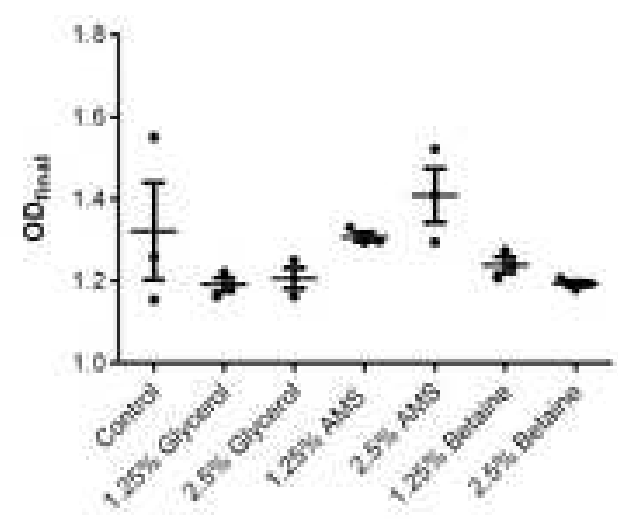

[Added Solute] (\% wiv or V/V)

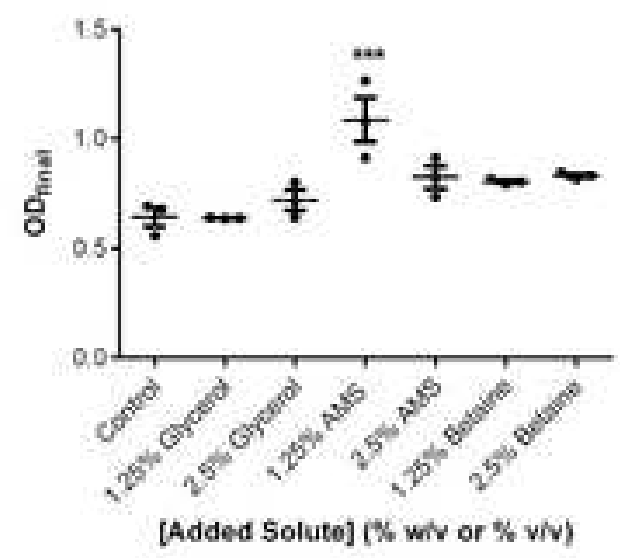



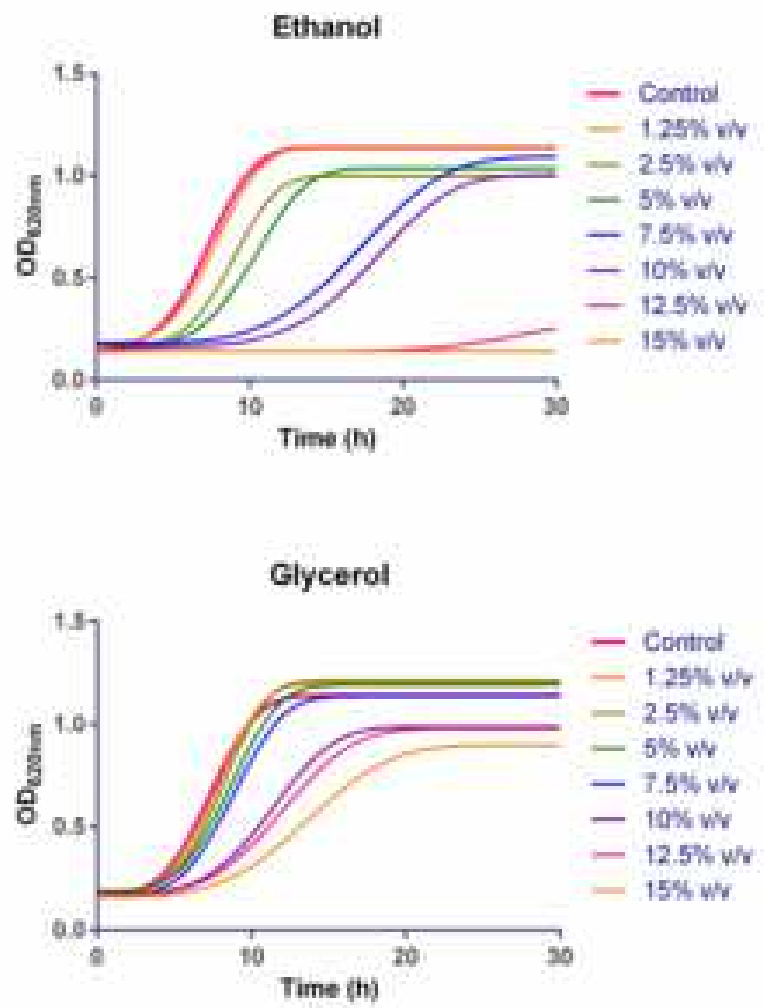

Supplementary Figure 51: Effects of chaotropes, kosmotropes and compatible solutes on the growth of S. cerevisiae NCYC 1088. These growth curves were used to derive the growth parameters

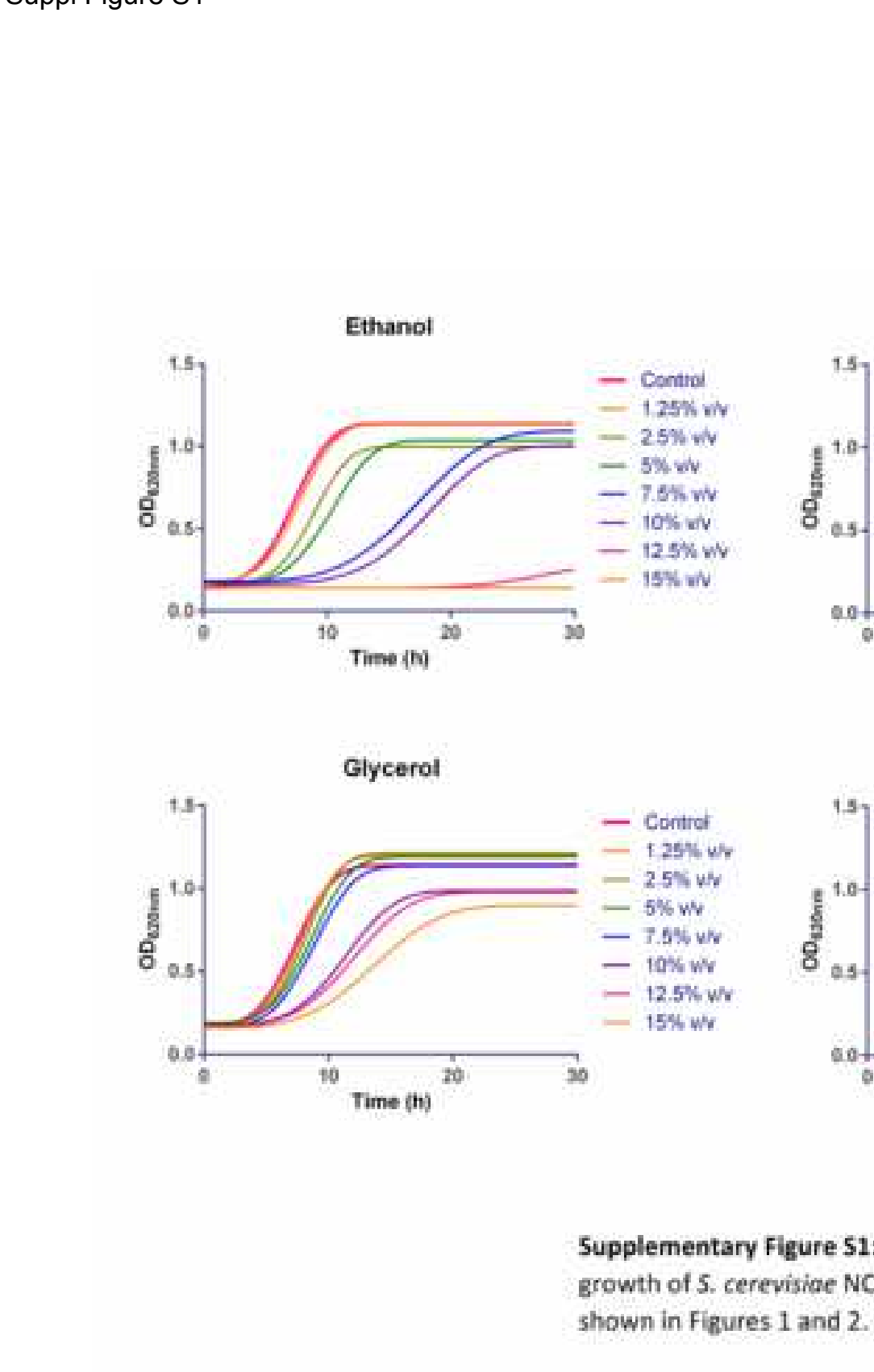
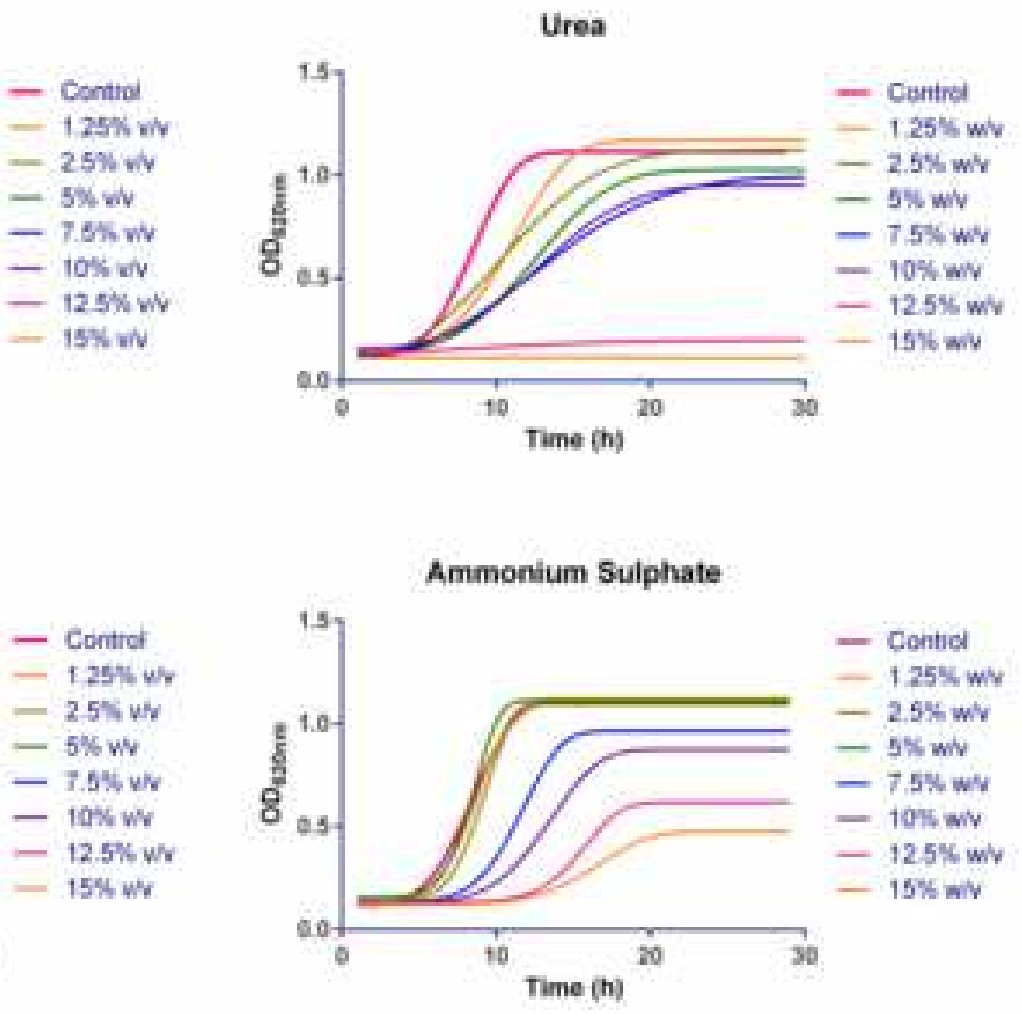

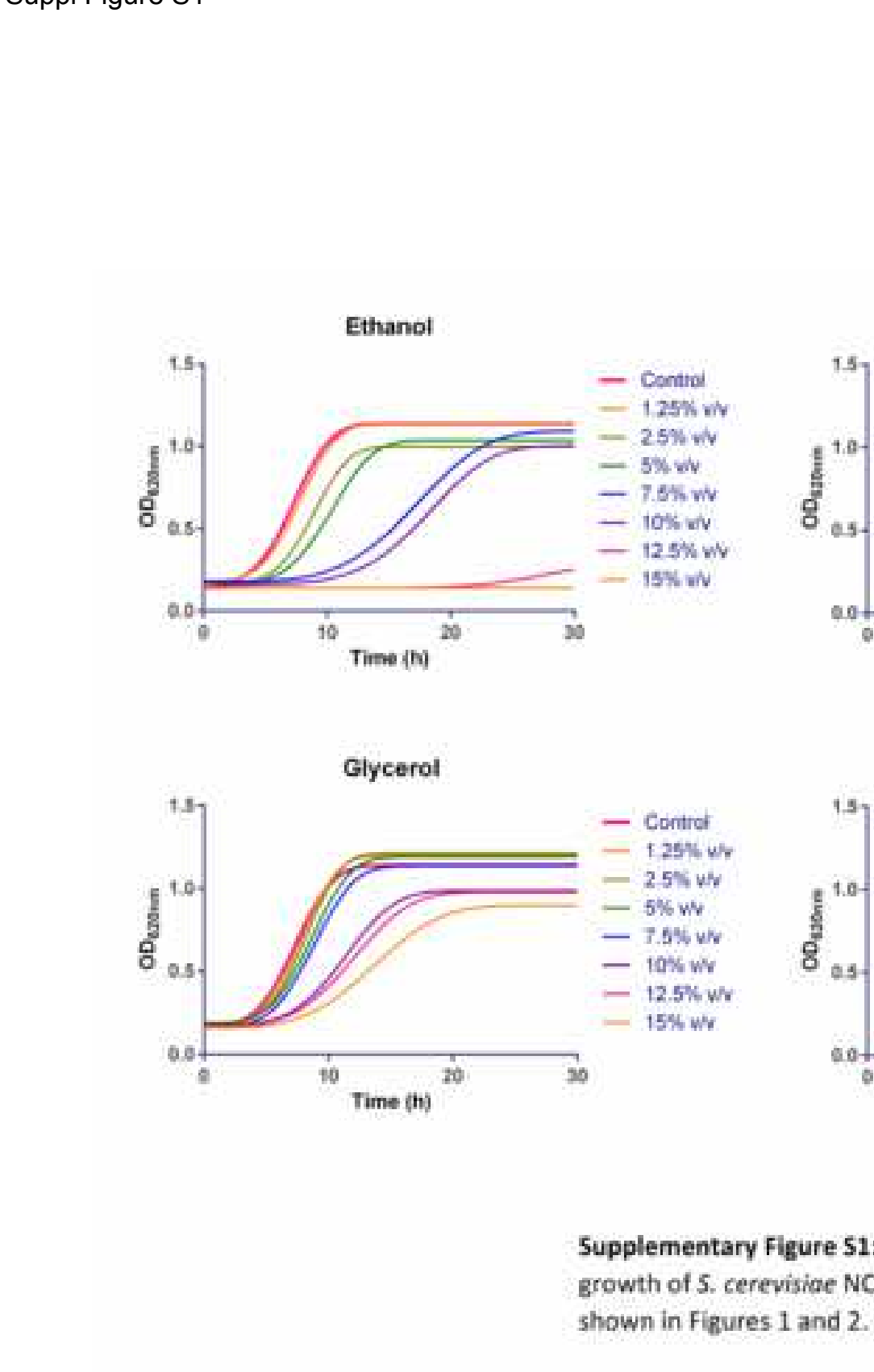

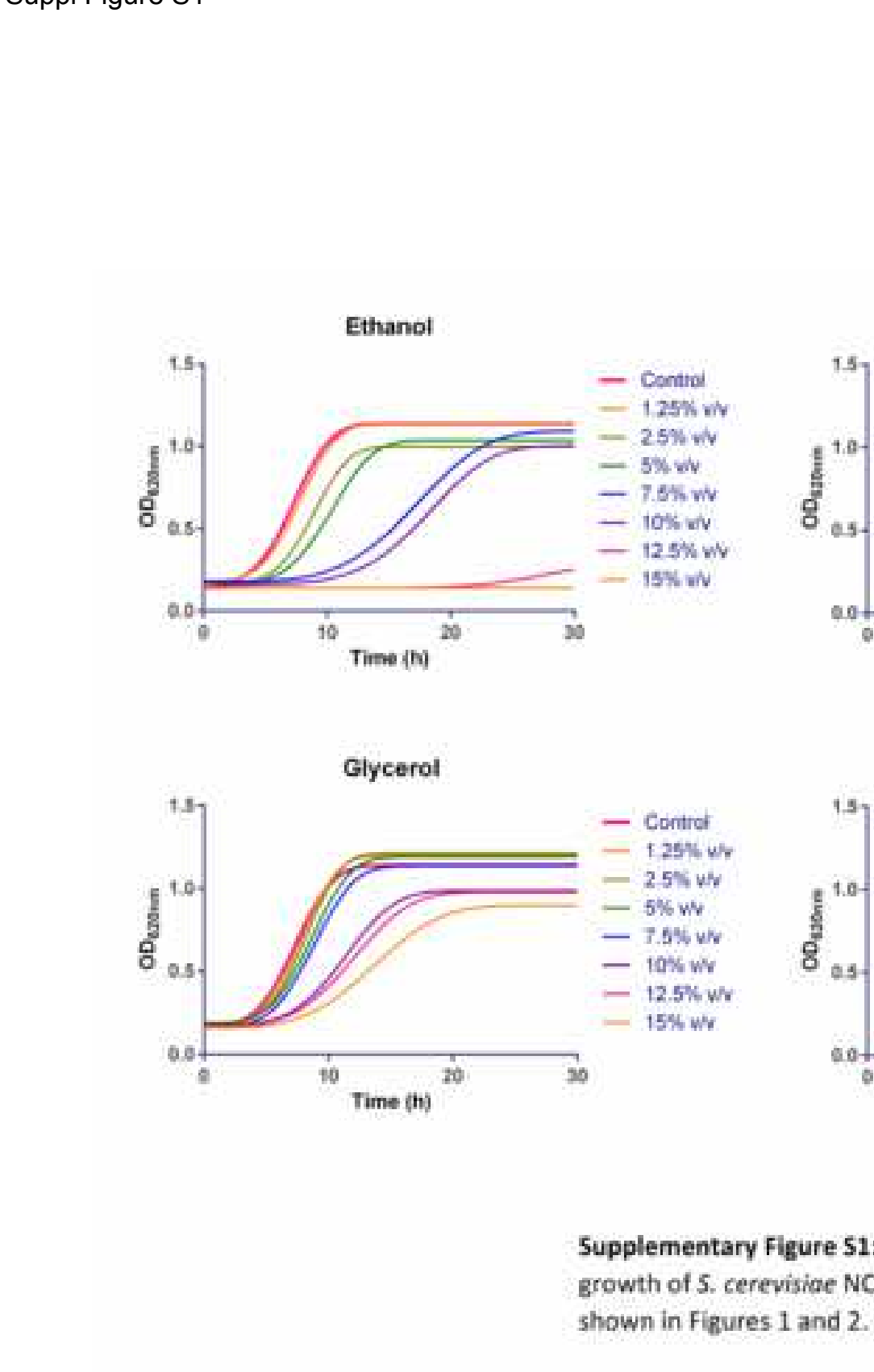

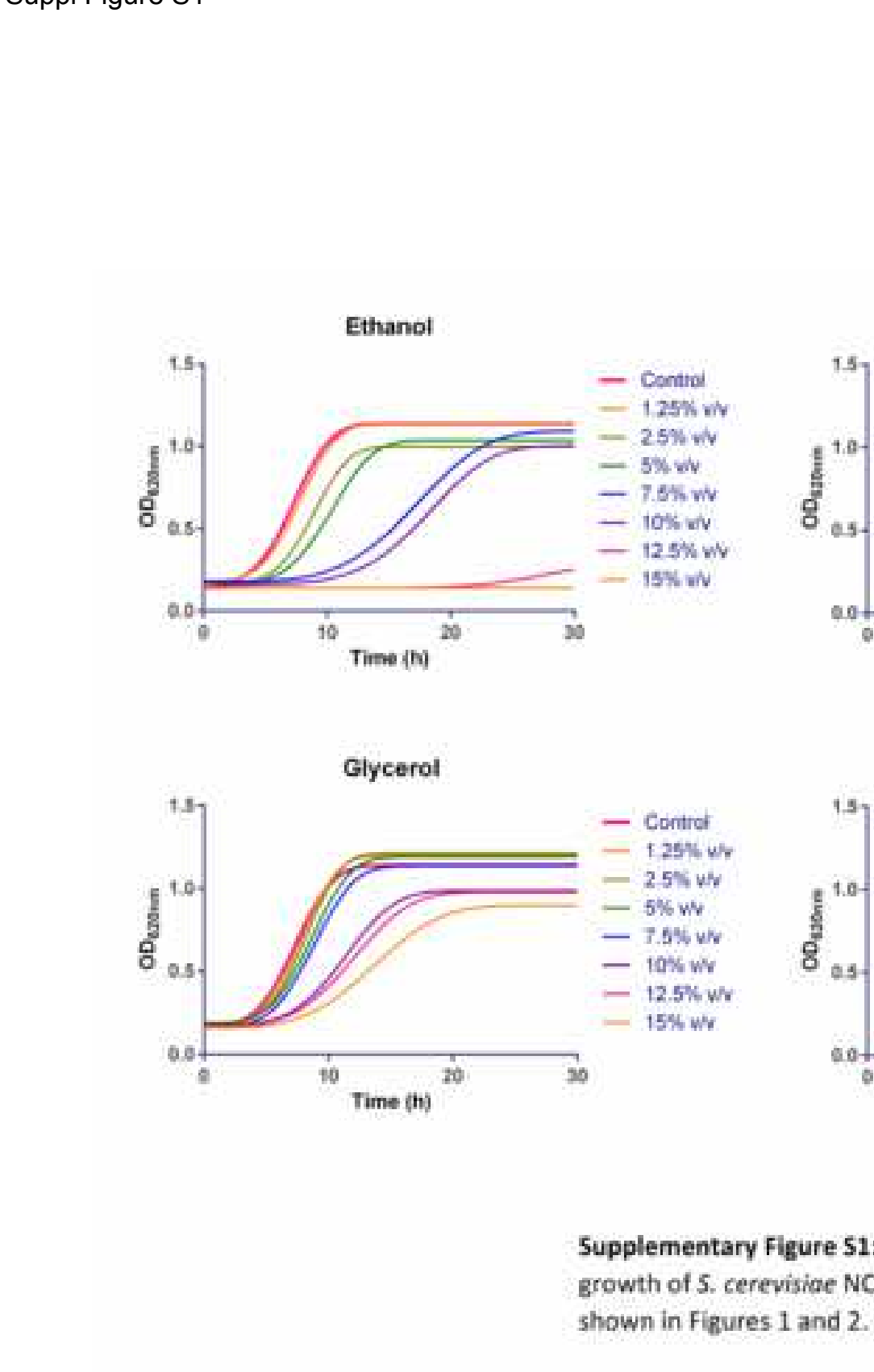

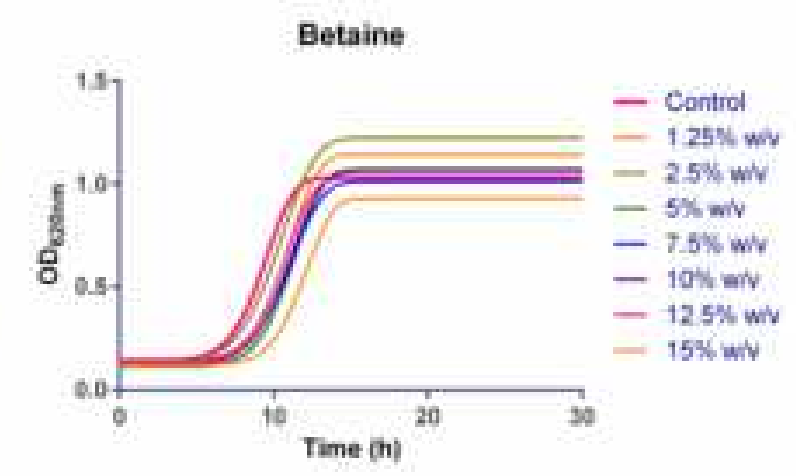

Click here to access/download;Figure;Suppl Fig S1.tif $\underline{\underline{\underline{\boldsymbol{}}}}$ 

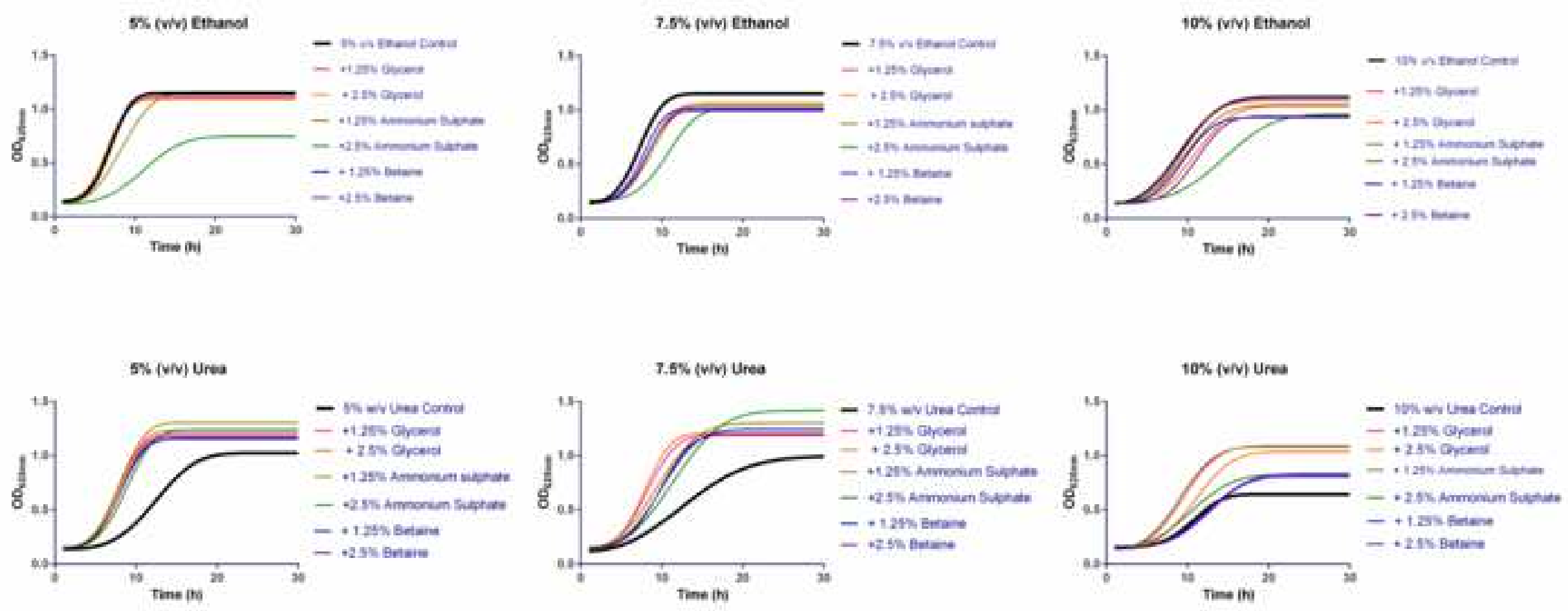

Supplementary Figure S2: Effects of kosmotropes and compatible solutes on the growth of 5 . cerevisioe NCYC 1088 when challenged with ethanol or urea. These data were used to obtain the growth parameters shown in Figures 3 and 4. 